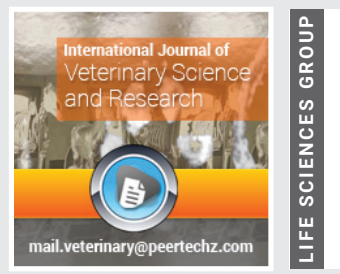

\section{Species complex of mosquitos captured by mechanical traps and an equine host}

\section{Clinton B Campbell' ${ }^{1}$, Daniel L Kline ${ }^{2 *}$, Jerome A Hogsette ${ }^{2}$ and Saundra H TenBroeck ${ }^{3}$}

\author{
'Department of Entomology and Nematology, University of Florida, Gainesville, FL 32611, USA \\ ${ }^{2}$ Department of Agriculture, Agricultural Research Service, Center for Medical, Agricultural, and \\ Veterinary Entomology, Gainesville, FL 32604, USA \\ ${ }^{3}$ Department of Animal Sciences, University of Florida, Gainesville, FL 32611, USA
}

Received: 02 April, 2020

Accepted: 11 December, 2021

Published: 13 December, 2021

*Corresponding author: Daniel L Kline, Department of Agriculture, Agricultural Research Service, Center for Medical, Agricultural and Veterinary Entomology, Gainesville, FL 32604, USA, Tel: 352-374-5933; Fax: 352-374-5922; E-mail: dan.kline@.usda.gov

Keywords: Mosquito magnet pro trap; Mosquito magnet liberty trap; Mosquito magnetX trap; CDC1012 trap; Culex nigripalpus

Copyright: @ 2021 Campbell CB, et al. This is an open-access article distributed under the terms of the Creative Commons Attribution License, which permits unrestricted use, distribution, and reproduction in any medium, provided the original author and source are credited.

https://www.peertechzpublications.com

\title{
Abstract
}

Field studies were conducted to evaluate the efficacy of commercially available mosquito traps to capture suspected West Nile Virus (WNV) vectors and compare the relative abundance, and species composition of mosquitoes captured by traps. Traps included the Mosquito Magnet (MM) Pro, MM-Liberty, MM-X, the CDC-1012, and the Home and Garden (HGM) prototype trap. In the first study, conducted at the University of Florida Horse Teaching Unit (HTU), Gainesville, FL, from May 17 to September 30 , 2002, the CDC-1012 caught significantly more mosquitoes than the other traps. The HGM trap did not catch any mosquitoes and was replaced with a horse on July 17. Percentages of WNV vector species captured in traps and vacuumed from the horse, respectively, were Culex nigripalpus Theobald $85-91 \%$ and $27 \%$, and Mansonia titillans (Walker) 2-5\% and 40\%. In the second study, performed for 5 days in April 2003, the MM-Pro, MM-X, and CDC-1012 traps caught significantly more mosquitoes than did the MM-Liberty trap. All traps captured primarily Cx. salinarius Coquillett, Cx. erraticus (Dyar and Knab), and Anopheles crucians Wiedemann. The horse attracted a greater percentage of Ma. titillans and less Cx. erraticus than did the mechanical traps. The mechanical traps may offer horses some degree of protection from suspected WNV species, however, a large number of Ma. titillans were recovered from the horse but the traps captured very few.

\section{Introduction}

West Nile Virus (WNV) is a mosquito-borne arbovirus of the family Flaviviridae. It infects birds primarily but can also infect humans and other animals such as horses. Infection can result in death. WNV was first reported in the US in Suffolk County, $\mathrm{NY}$, in 1999 [1]. It subsequently spread across the country to the Pacific coast and is a major threat to equine health. In Florida, Culex salinarius Coquillett and Cx. nigripalpus Theobald are considered to be the major vectors in the spring and in the late summer and fall, respectively [2].

WNV was first detected in Jefferson County, FL, on July 3, 2001, when a dead crow was confirmed positive for the virus [3]. Between 2001 and 2003, 1,108 (5.4\%) of the clinical WNV equine cases in the US were reported from Florida [4]. Although that number has decreased in recent years, WNV continues to be a threat to Florida's multibillion-dollar equine industry.
Most of the data linking mosquitoes to equine hosts have come from blood-meal assays and traps placed in stables [5]. Although horses appear to be a favorite host for a few species, such as Aedes vexans (Meigen) [6], many other species feed on horses occasionally. These include Anopheles crucians Wiedemann, Coquillettidia perturbans (Walker), Culiseta inornata (Williston), Cx. quinquefasciatus Say, Cx. salinarius, Cx. tarsalis Coquillett, Psorophora columbiae (Dyar and Knab), Ps. ferox (von Humboldt) [7], Cx. nigripalpus [8] and Ae. dorsalis (Meigen) [9]. Some of these species, primarily the Culex spp., have been listed as competent WNV vectors under laboratory conditions [10].

Because WNV has become a problem across the US, research in monitoring techniques is warranted. When the primary vectors have been better defined, appropriate surveillance methods can be employed by mosquito abatement districts to target these species. Mosquito surveillance traps, some of 
which are promoted by their manufacturers to provide some degree of protection from WNV vectors, could play a role in the collection of pertinent mosquito species. The objective of this study was to determine if an attraction differential exists between an equine host and selected commercial mosquito traps sold for surveillance and control of putative WNV vectors. These include the counterflow geometry traps sold under the Mosquito Magnet name and the ubiquitous CDC trap. The question to be answered is do the horse and the traps attract the same species complex of mosquitos.

\section{Materials and methods}

\section{Study site}

Trapping was performed at the University of Florida Horse Teaching Unit (HTU) (Figure 1), a 26-ha equine facility located $5 \mathrm{~km}$ south of the main campus. The HTU maintains a Quarter Horse herd of varying ages. The study site was selected because of the high mosquito pressure, the presence of numerous small ponds, and nearby wetlands with low lying areas that have a tendency to flood during rainy periods.

\section{Traps}

The CDC-1012 trap (John W. Hock Company, Gainesville, FL) attracts mosquitoes with a 6.3-Watt incandescent light plus $\mathrm{CO}_{2}$ and pulls them into a catch container with a small in-line fan (Figure $2 \mathrm{~A}$ ). The trap is powered by a rechargeable $6-\mathrm{v}$ battery and $\mathrm{CO}_{2}$ is supplied by compressed gas cylinders at a rate of $500 \mathrm{ml} / \mathrm{min}$. For our study, the $\mathrm{CO}_{2}$ line was taped to the underside of the trap lid above the fan. A polypropylene container with a 30-mesh screen bottom was used to hold the captured mosquitoes.

The Mosquito Magnet (MM) X is an American Biophysics Corporation (ABC) (North Kingston, RI) Counterflow Geometry (CFG) trap [11] (Figure 2B). The $\mathrm{CO}_{2}$ from compressed gas cylinders was supplied at a rate of $500 \mathrm{ml} / \mathrm{min}$. The trap has a clear PVC shell, with removable top and bottom lids to allow access to the trapped insects. The trap has two fans powered by a $12-v$ battery.

The Home and Garden (HGM) prototype trap (BugJammer Inc., Pennington, NJ) (Figure $2 \mathrm{C}$ ) has acoustical and visual

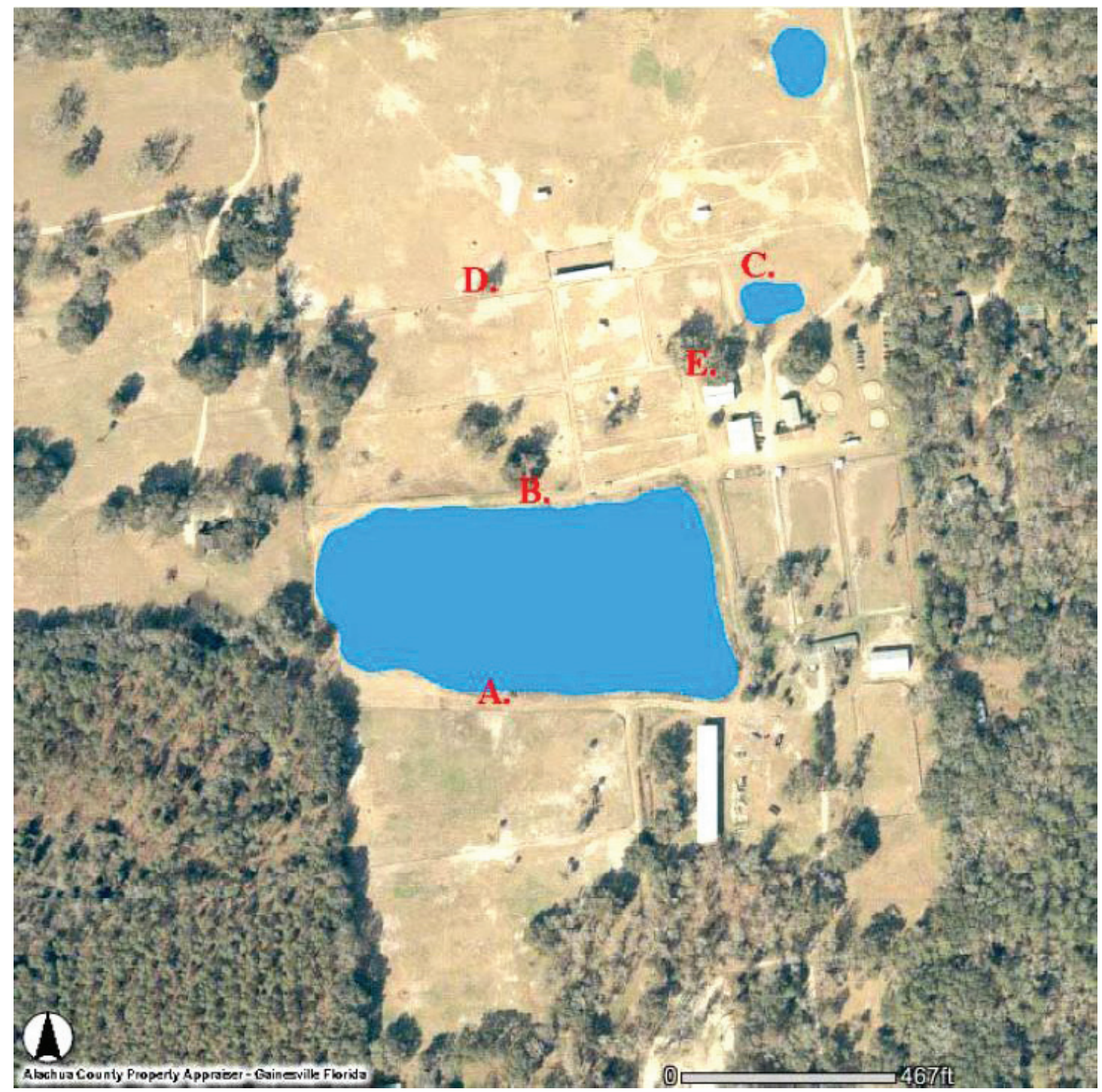

Figure 1: Aerial photograph of the University of Florida Horse Teaching Unit showing the five trap sites.

Citation: Campbell CB, Kline DL, Hogsette JA, TenBroeck SH (2021) Species complex of mosquitos captured by mechanical traps and an equine host. Int J Vet Sci Res 7(2): 169-177. DOI: https://dx.doi.org/10.17352/ijvsr.000097 
cues for attracting mosquitoes and other insects. The unique attractant is the digitized recording of the heartbeat of a dog, which is emitted from a speaker. Electrical power is supplied by four D-cell batteries. Visual attractants include light reflected in the ultraviolet and visible ranges and contrasting black and white vertical stripes. Insects are captured on a cylindrical white adhesive sleeve placed around the housing over the speaker.

The MM-Pro (Figure 2D) is another ABC CFG trap. This trap catalytically converts propane into 3 attractants: $\mathrm{CO}_{2}$, heat, and moisture. Propane is supplied by a standard 20lb commercial tank. The trap also generates its own power through a thermoelectric module, which allows for standalone operation. The MM-Pro is constructed of stainless steel with a PVC shell. Captured mosquitoes are retained in a nylon net within the trap.

The MM-Liberty (Figure $2 \mathrm{E}$ ), another ABC CFG trap, is similar in form and function to the MM-Pro, however, the power supply is normally $120-\mathrm{v}$ US alternating current. Because the traps used in this project had to be completely portable, the trap was modified by fitting its electric cord with an adaptor so the trap could be connected to a rechargeable 12-v battery. Like the MM-Pro, the MM-Liberty creates $\mathrm{CO}_{2}$ from propane combustion and mosquitoes are retained in a nylon net located inside the trap.

\section{Horses}

Two adult geldings were used to attract mosquitoes so their mosquito species profiles could be compared with those of the traps. From July 17 - August 18, 2002, a cremelo gelding was used, and from August 19-September 30, 2002, and April 2003, a chestnut gelding was used. Mosquitoes that landed on the horse were captured with a BioQuip (Rancho Dominguez, CA) portable vacuum aspirator, powered by a cigarette lighter in a vehicle. Capture canisters fit snugly inside the aspirator and the vacuum holds mosquitoes inside the canister when the power is on. A cap is placed over the canister before the vacuum is switched off.

\section{Experimental design}

At the HTU, traps were set in a $5 \times 5$ Latin square design, placed at 1 of 5 pre-selected sites prior to the first trapping interval then rotated sequentially through the remaining sites after each interval to constitute 1 replication. Traps were placed as follows: on opposite sides of a small pond (Figure $1 \mathrm{~A}$ and $\mathrm{B}$ ), near a second small pond (Figure $1 \mathrm{C}$ ), along a pasture fence line (Figure 1D), near a large oak tree and horse barn (Figure 1E).

In the first study conducted from May 17- September 30, 2002, 5 different traps were operated then rotated through trap sites as described above. Traps were operated one night per week and then one consecutive 5-night period each month. Trapping began 2-3 $\mathrm{h}$ before sunset and ended $2-3 \mathrm{~h}$ after dawn. On July 17, 2002, the HGM trap was removed from the study and replaced with a horse. The horse was led each night to the site previously designated for the HGM trap, and mosquitoes were vacuumed from the horse for $30 \mathrm{~min}$, starting
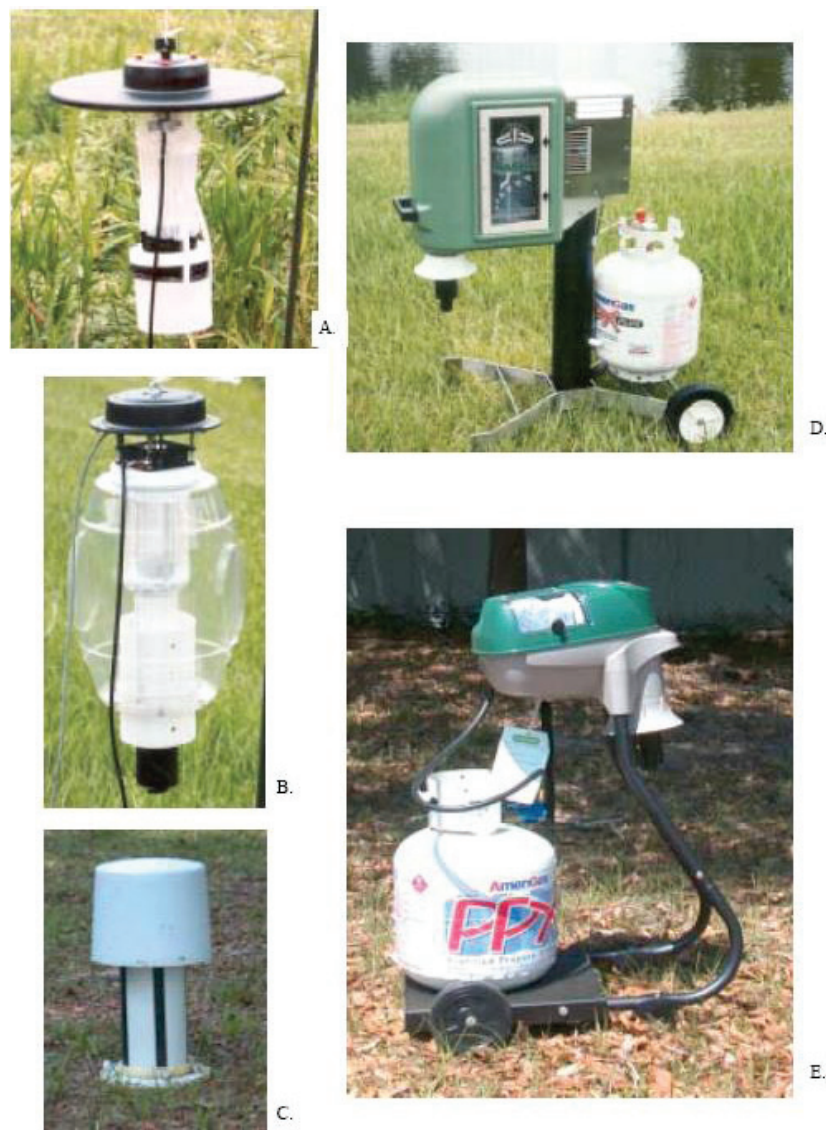

Figure 2: Five mosquito traps evaluated at the University of Florida Horse Teaching Unit: A. CDC-1012; B. Mosquito Magnet-X; C. Home and Garden Mosquito prototype trap; D. Mosquito Magnet Pro; E. Mosquito Magnet Liberty.

approximately 15 minutes before sunset and ending 15 minutes after sunset. The remaining traps were operated through the night as previously described.

The second study, also a $5 \times 5$ Latin square design, was conducted on April 7, 8, 9, 15, and 16, 2003, to compare the MM-Pro, MM-Liberty, MM-X, CDC-1012, and a horse. All traps were started approximately 15 minutes before dusk and were collected 15 minutes after dusk. Meanwhile, mosquitoes were vacuumed from the horse during the same interval. Traps were emptied after the 30-minute interval, then remained operational overnight. The contents were collected the following morning. The traps and the horse were rotated after each trapping interval so that each occupied every site once during the 5-day experiment.

Captured mosquitoes were returned to the laboratory, euthanized and stored in a freezer. Identifications were made by C.B.C. using the keys of Darsie and Ward [12].

\section{Data analysis}

Numbers of mosquitoes captured were subjected to analysis by GLM after transformation by $\log 10(n+1)$; means were originally separated using Fisher's Least Significant Difference Test [13]. However, there are more appropriate tests for this purpose and significance levels resulting from the Fisher's test have been disregarded. Unfortunately, raw data have been lost over the years and an updated analysis cannot be performed. 
Therefore, only numeric inferences will be made by means. To indicate the degree of diversity in the mosquito populations, a Shannon-Weaver index [14] was calculated using the following function:

$$
\mathrm{H}^{\prime}=-\sum p_{i} \ln p_{i}
$$

where $p_{i}=$ the proportion of the number of individuals of species $i$ in the total sample number $(n i / \mathrm{N})$, and $\ln p_{i}=\log 10 p_{i}$.

\section{Results}

\section{Study 1}

The total number of mosquitoes collected from May 17-September 30, 2002, was 272,034. During these studies, the CDC-1012 trap captured a mean number of 2,875 mosquitoe,s which was approximately $2 \mathrm{X}$ greater than those captured by any of the three CFG traps; the CFG trap means were clustered within a range of 245 mosquitoes, with the MM-liberty trap having the highest value and the MM-Pro trap the lowest (Table 1). The BugJammer trap did not have a $\mathrm{CO}_{2}$ source and did not catch any mosquitoes during the study.

From May 17 - July 16, 2002, 9 species of mosquitoes were captured in the largest numbers, with no single species dominating the percentages captured (Table 2). However, the three traps that captured the highest percentages $(\geq 20 \%)$ of $C x$. salinarius were the $\mathrm{CDC}-1012$, the MM-Pro, and the MM-X. The species captured in the highest percentage $(30 \%)$ by the MM-Liberty was $C x$. nigripalpus, but the second highest was Cq. perturbans. Although the species captured in the highest percentage by the $\mathrm{CDC}-1012$ was $C x$. salinarius, surprisingly, the second highest was Ma. titillans (Walker) (Table 2). The largest total number of mosquitoes was captured by the MMPro and the smallest by the MM-Liberty. The total number of mosquitoes captured during this period by all four traps was 1,046 .

During the remainder of study 1 , from July 17 September 30, 2002, Cx. nigripalpus was captured in the highest percentages by the traps; however, Ma. titillans, Cx. nigripalpus, and Ae. infirmatus (Dyar and Knab) were the species captured in the highest percentages from the horse (Table 3). Mansonia. titillans and Ae. infirmatus were also captured in the mechanical traps, but they did not constitute more than 4.7 and $1.6 \%$, respectively, of any trap catch. A lower percentage of $C x$. nigripalpus, but higher percentages of Ae. infirmatus, and Psorophora spp. were vacuumed from the horse than were captured in any of the traps. A total of 18 different species were trapped during this study, including Ae. albopictus (Skuse), Ae. vexans, An. crucians, An. quadrimaculatus Say, Cx. erraticus (Dyar and Knab), Cx. nigripalpus, Cx. salinarius, $C x$. quinquefasciatus, $C q$. perturbans, Ma. titillans, Ae. infirmatus, Ae. mitchellae (Dyar), Ps. ciliata (Fabricius), Ps. columbiae, Ps. cyanescens (Coquillett), Ps. howardii Coquillett, and Uranotaenia lowii Theobald, however, only the species constituting $\geq 0.03 \%$ of the total catch are shown (Table 3).

The relative abundance of 4 major species groups trapped from May 17-Sept 30, 2002, at each trapping site was very similar. Between 85 and $92 \%$ of all mosquitoes captured at all sites was Cx. nigripalpus (Table 4). Mansonia titillans, Ae. infirmatus, Psorophora spp. and other various species constituted between 7.3 and $0.69 \%$ of the catches at all sites.

Species diversity from May 17-July 16, 2002, as indicated by the Shannon-Weaver Diversity Index, was lowest for the MM-Liberty (0.84) and ranged between 0.87 and 0.93 among

Table 1: Mean \pm SE and total numbers of mosquitoes trapped during 39 overnight trapping intervals at the UF Horse Teaching Unit from May 17 - September 30, 2002.

\begin{tabular}{|c|c|c|c|}
\hline Traps & $\boldsymbol{n}$ & Mean number \pm SE & Total number \\
\hline CDC-1012 & 38 & $2,874.7 \pm 795.5$ & 109.238 \\
\hline MM-X & 37 & $1,555.0 \pm 437.8$ & 57.535 \\
\hline MM-Pro & 34 & $1,401.1 \pm 478.2$ & 47.639 \\
\hline MM-Liberty & 35 & $1,646.3 \pm 532.1$ & 57.622 \\
\hline
\end{tabular}

Note: $n=$ Number of trapping intervals when traps were operating properly.

Table 2: Percentage of mosquito species and total numbers of mosquitoes captured by each trap during 18 overnight trapping intervals at the University of Florida Horse Teaching Unit, May 17, 2002-July 16, 2002.

\begin{tabular}{|c|c|c|c|c|}
\hline Traps & \multicolumn{5}{|c|}{} \\
\hline Species & CDC-1012 & MM-Liberty & MM-Pro & MM-X \\
\hline Cx. nigripalpus & 14.86 & 30.41 & 18.87 & 17.43 \\
\hline Ma. titillans & 20.88 & 8.78 & 12.50 & 10.79 \\
\hline Ae. vexans & 4.02 & 3.38 & 9.56 & 3.73 \\
\hline An. crucians & 8.03 & 1.35 & 2.21 & 6.22 \\
\hline Cq. perturbans & 16.87 & 24.32 & 5.64 & 14.52 \\
\hline Cx. erraticus & 4.02 & 5.41 & 6.13 & 10.79 \\
\hline Cx. salinarius & 22.49 & 7.43 & 24.26 & 20.33 \\
\hline Ps. columbiae & 5.22 & 8.11 & 5.88 & 2.49 \\
\hline Ae. infirmatus & 1.20 & 8.78 & 12.50 & 9.54 \\
\hline Other & 2.41 & 2.03 & 2.45 & 4.15 \\
\hline Total catch & 249 & 148 & 408 & 241 \\
\hline
\end{tabular}

Table 3: Percentage of mosquito species and total numbers of mosquitoes captured by each trap and vacuumed from a horse during 21 overnight trapping intervals at the University of Florida Horse Teaching Unit, July 17, 2002-September 30, 2002.

\begin{tabular}{|c|c|c|c|c|c|}
\hline \multicolumn{5}{|c|}{ Traps } \\
\hline Species & CDC-1012 & MM-Liberty & MM-Pro & MM-X & Horse \\
\hline Cx. nigripalpus & 88.56 & 91.13 & 86.69 & 85.73 & 27.26 \\
\hline Ma. titillans & 4.73 & 1.82 & 2.24 & 4.40 & 39.76 \\
\hline Ae. vexans & 0.22 & 0.06 & 2.83 & 0.26 & 0.66 \\
\hline An. crucians & 1.37 & 0.45 & 0.64 & 0.97 & 0.07 \\
\hline Cq. perturbans & 0.24 & 0.31 & 0.12 & 0.16 & 3.06 \\
\hline Cx. erraticus & 1.57 & 1.59 & 1.76 & 1.35 & 0.27 \\
\hline Cx. salinarius & 0.15 & 0.10 & 1.07 & 0.64 & 0.40 \\
\hline Ps. ciliata & 0.03 & 0.09 & 0.15 & 0.17 & 0.73 \\
\hline Ps. columbiae & 1.09 & 2.15 & 2.40 & 2.18 & 3.86 \\
\hline Ps. cyanescens & 0.04 & 0.03 & 0.09 & 0.24 & 6.65 \\
\hline Ae. infirmatus & 1.54 & 1.62 & 1.52 & 1.49 & 15.63 \\
\hline Other & 0.44 & 0.65 & 0.49 & 2.42 & 1.66 \\
\hline Total catch & 108.989 & 57.474 & 47.229 & 57.294 & 1.504 \\
\hline & & & & & 172 \\
\hline
\end{tabular}

Citation: Campbell CB, Kline DL, Hogsette JA, TenBroeck SH (2021) Species complex of mosquitos captured by mechanical traps and an equine host. Int J Vet Sci Res 7(2): 169-177. DOI: https://dx.doi.org/10.17352/ijvsr.000097 
the remaining traps (Table 5). When the horse was included in the trapping design, from July 17-Sept 30, 2002, the species diversity for the horse was higher (0.69) than those of all three traps $(0.23-0.30)$.

\section{Study 2}

In the $30-$ min trapping studies, the mean trap counts ranged from 21.8-91.6 mosquitoes, with a mean of 28.4 mosquitoes collected from the horse. The highest mean numbers of mosquitoes were captured by the MM-Pro, CDC1012, and MM-X traps, and the lowest by the MM-Liberty trap (Table 6). The mosquito means for the horse (28.4) and the MM-Liberty trap (21.8) were relatively close, but the difference between the mosquito means for the MM-Pro, CDC-1012, and $\mathrm{MM}-\mathrm{X}$ traps and the mosquito mean for the horse were $\geq 2 \mathrm{X}$ (Table 6). The total mosquitoes captured from the 4 traps and the horse for 5 catch periods was 1,336 .

The percentages of the various mosquitoes captured during the 30-min studies differed between the traps and the horse. Although the most abundant species for all traps was $C x$. salinarius, the range of percent capture differed among traps (Table 7). The CFG traps captured $65.8-80.1 \%$ Cx. salinarius, but only 40.1 and $49.2 \% C x$. salinarius were vacuumed from the horse and captured by the CDC-1012, respectively. Mansonia titillans recovered from the horse and trapped by the CDC-1012 represented 29.58 and $19.70 \%$, respectively, of the total mosquitoes captured, but just $41-9.17 \% M$. titillans were captured by the CFG traps. The horse attracted a higher percentage of Ae. vexans than did the traps, but the traps attracted a higher percentage of $C x$. erraticus than did the horse. An. crucians abundance varied among all traps, ranging from 4.37 to $16.80 \%$ (Table 7 ).

The overnight mean catches showed a distinct division between the MM-Liberty and the other traps with the MMLiberty catching $\geq 3 \mathrm{X}$ fewer mosquitoes (mean $=114.6$ per night) than any other trap (Table 8 ). The mean catches of traps other than the MM-Liberty ranged between 342.4 and 493.4 mosquitoes per night. The total catch for all traps during the 5-night trapping period was 6,693.

The relative abundance of mosquito species captured differed somewhat between the MM-Pro and the other traps in the 2003 overnight trial. Between 54 and $68 \%$ of all mosquito species captured in traps other than the MM-Pro were $C x$. salinarius (Table 8). However, the MM-Pro had $84.58 \%$ CX. salinarius, and no other species it captured represented $>7 \%$ of the total count. The other traps caught a greater percentage of Cx. erraticus and An. crucians than did the MM-Pro. Ma. titillans was $\leq 3 \%$ of the mosquito species in any trap (Table 8 ).

The April trapping study yielded 16 species of mosquitoes. These included Ae. albopictus, Ae. vexans, An. crucians, An quadrimaculatus, Cq. perturbans, Cx. erraticus, Cx. nigripalpus, $C x$. salinarius, Ma. titillans, Ps. ciliata, Ps. columbiae, Ps. ferox, Ae. infirmatus, Ae. mitchellae, Ur. lowii, and Ur. sapphrina (Osten Sacken) (Table 8).
Table 4: Total numbers of mosquitoes and percentage of mosquito species captured at each trapping site at the University of Florida Horse Teaching Unit, May 17 -September 30, 2002.

\begin{tabular}{|c|c|c|c|c|c|c|}
\hline Trapp & Total & $\%$ Cx. & $\%$ Ma. & $\%$ Ae. & $\%$ Ps. & $\%$ \\
\hline site & mosquitoes & nigripalpus & titillans & infirmatus & spp. & Other \\
\hline A & 74,742 & 85.30 & 3.70 & 2.65 & 3.14 & 5.21 \\
\hline B & 56,415 & 84.54 & 4.69 & 1.61 & 1.86 & 7.34 \\
\hline C & 57,780 & 90.41 & 3.28 & 1.47 & 0.91 & 5.07 \\
\hline D & 47,702 & 88.07 & 5.42 & 0.69 & 2.03 & 5.50 \\
\hline E & 36,899 & 91.82 & 1.70 & 1.19 & 1.77 & 4.87 \\
\hline
\end{tabular}

Note: For trap site locations, see Figure 1.

Table 5: Shannon-Weaver Diversity Indices of mosquito species trapped or vacuumed from a horse at the University of Florida Horse Teaching Unit.

\begin{tabular}{|c|c|c|c|c|}
\hline Traps & A & B & C & D \\
\hline CDC-1012 & 0.87 & 0.24 & 0.63 & 0.54 \\
\hline MM-Liberty & 0.84 & 0.23 & 0.46 & 0.48 \\
\hline MM-Pro & 0.90 & 0.29 & 0.37 & 0.28 \\
\hline MM-X & 0.93 & 0.30 & 0.51 & 0.48 \\
\hline Horse & - & 0.70 & 0.69 & - \\
\hline
\end{tabular}

Note: $A=$ Study 1 , trapping from May $17-J u l y ~ 16,2002 ; B=$ Study 1 , trapping from July 17-Sept 30, 2002; C = Study 2, 30-minute trapping in April 2003; D = Overnight trapping in April 2003

Table 6: Mean \pm SE and total numbers of mosquitoes trapped in five 30-minute trapping intervals at the UF Horse Teaching Unit, April 2003.

\begin{tabular}{|c|c|c|}
\hline Traps & Mean \pm SE & Total number \\
\hline MM-Pro & $91.6 \pm 40.9$ & 458 \\
\hline CDC-1012 & $72.6 \pm 10.0$ & 264 \\
\hline MM-X & $52.8 \pm 38.5$ & 363 \\
\hline Horse & $28.4 \pm 7.8$ & 142 \\
\hline MM-Liberty & $21.8 \pm 14.4$ & 109 \\
\hline
\end{tabular}

Table 7: Percentage of mosquito species and total numbers of mosquitoes captured by each trap and vacuumed from a horse in five 30-minute trapping intervals at the University of Florida Horse Teaching Unit, April 2003.

\begin{tabular}{|c|c|c|c|c|c|}
\hline Mosquito & \multicolumn{5}{|c|}{ Traps } \\
\hline species & CDC-1012 & MM-Liberty & MM-Pro & MM-X & Horse \\
\hline Ae. vexans & 1.52 & 0.00 & 2.40 & 1.38 & 7.04 \\
\hline An. crucians & 13.26 & 8.26 & 4.37 & 16.80 & 9.86 \\
\hline An. quadrimaculatus & 0.38 & 0.00 & 0.00 & 0.28 & 3.52 \\
\hline Cq. perturbans & 1.52 & 0.92 & 0.00 & 2.75 & 3.52 \\
\hline Cx. erraticus & 9.09 & 6.42 & 2.18 & 6.06 & 1.41 \\
\hline Cx. nigripalpus & 0.00 & 0.92 & 3.71 & 0.28 & 0.00 \\
\hline Cx. salinarius & 49.24 & 70.64 & 80.13 & 65.84 & 40.14 \\
\hline Ma. titillans & 19.70 & 9.17 & 5.02 & 4.13 & 29.58 \\
\hline Ae. infirmatus & 5.30 & 3.67 & 1.97 & 1.93 & 4.93 \\
\hline Other & 0.00 & 0.00 & 0.22 & 0.55 & 0.00 \\
\hline Total catch & 264 & 109 & 458 & 363 & 142 \\
\hline
\end{tabular}

Relative abundance of mosquito species captured was similar for each site. Cx. salinarius was the primary species captured at each site, ranging between 60.7 and $75.2 \%$ of

Citation: Campbell CB, Kline DL, Hogsette JA, TenBroeck SH (2021) Species complex of mosquitos captured by mechanical traps and an equine host. Int J Vet Sci Res 7(2): 169-177. DOI: https://dx.doi.org/10.17352/ijvsr.000097 
the species composition (Table 9). Other species of a higher percentage capture were $C x$. erraticus and An. crucians.

Species diversity, as indicated by the Shannon-Weaver Diversity Index, was lowest for the MM-Pro traps during the 30-minute (0.37) and overnight (0.28) trapping studies. In the 30-minute trapping studies, the species diversity was higher for mosquitoes vacuumed from the horse (0.69) than for those captured in the traps (0.37-0.63) (Table 5).

\section{Discussion}

\section{Species composition and diversity}

North Florida has a unique mosquito species composition where $C x$. salinarius occurs in high numbers during the winter and spring, and $C x$. nigripalpus occurs primarily in the summer and fall. It is speculated that WNV-positive $C x$. salinarius are overwintering the virus, and when spring temperatures are particularly warm, a large outbreak of WNV could occur in north Florida because of the early occurrence of $C x$. nigripalpus [2]. This is one reason why monitoring devices, such as the traps used in this study, are important for early detection of a possible viral outbreak. Data from both studies performed at the HTU showed that $\mathrm{Cx}$. salinarius was captured in spring (Table 8 ) and Cx. nigripalpus was the primary mosquito captured in the summer and fall months (Table 3). This is in agreement with

Table 8: Percentage of total, the total, and the mean \pm SE numbers of mosquitoes captured by each trap during 5 overnight trapping intervals at the University of Florida Horse Teaching Unit, April 2003.

\begin{tabular}{|c|c|c|c|c|}
\hline \multicolumn{5}{|c|}{ Traps } \\
\hline Species & CDC-1012 & MM-Liberty & MM-Pro & MM-X \\
\hline Ae. vexans & 0.49 & 0.52 & 0.58 & 1.08 \\
\hline An. crucians & 17.67 & 10.82 & 6.19 & 15.35 \\
\hline An. quadrimaculatus & 0.32 & 1.05 & 0.53 & 1.44 \\
\hline Cq. perturbans & 1.78 & 2.27 & 0.41 & 1.80 \\
\hline Cx. erraticus & 21.24 & 16.23 & 6.31 & 9.02 \\
\hline Cx. nigripalpus & 0.04 & 0.00 & 0.06 & 0.26 \\
\hline Cx. salinarius & 54.20 & 67.95 & 84.58 & 67.59 \\
\hline Ma. titillans & 2.92 & 1.40 & 0.82 & 2.11 \\
\hline Ae. infirmatus & 1.13 & 1.05 & 0.35 & 0.77 \\
\hline Other & 0.20 & 0.70 & 0.18 & 0.57 \\
\hline Total catch & 2,467 & 573 & 1,712 & 1,941 \\
\hline Mean catch & $493.4 \pm 158.0$ & $114.6 \pm 133.0$ & $342.4 \pm 114.6$ & $388.2 \pm 122.1$ \\
\hline
\end{tabular}

Table 9: Percent of total catch of mosquito species by trap site. The trapping study was conducted overnight at the UF Horse Teaching Unit during April 2003.

\begin{tabular}{|c|c|c|c|c|c|c|c|}
\hline Trap & Total & An. & Cq. & Cx. & Cx. & Ma. & \\
\hline site & catch & crucians & perturbans & erraticus & salinarius & titillans & Other \\
\hline A & 2159 & 12.69 & 1.57 & 15.15 & 65.63 & 2.45 & 2.52 \\
\hline B & 2225 & 16.90 & 1.21 & 16.67 & 60.76 & 2.38 & 2.06 \\
\hline C & 923 & 10.83 & 1.41 & 8.78 & 73.35 & 0.76 & 4.88 \\
\hline D & 1198 & 11.27 & 1.67 & 7.76 & 75.21 & 1.59 & 2.50 \\
\hline E & 1188 & 9.04 & 2.66 & 14.89 & 68.09 & 1.60 & 3.72 \\
\hline
\end{tabular}

Note: Trap sites are shown on HTU map in Figure 1. data from other areas in Florida $[2,15]$ and previous research performed at or near the HTU $[16,17]$.

The relative composition of mosquito species feeding upon the horses differed from that of any of the mechanical traps, despite the horse being rotated through the same trapping sites as the traps. The composition of species in the spring would indicate that $C x$. salinarius was the vector of interest most readily trapped in mechanical traps at the HTU (Table 7). Cx. salinarius is known to feed readily on both avian and mammalian hosts [18], thus the possibility of finding it both in the traps and on the horse seems quite probable during periods of peak emergence. A higher percentage of $C x$. salinarius was found in the mechanical traps $(49.24-80.13 \%)$ than on the horse $(40.14 \%)$, but $\mathrm{Cx}$. salinarius was the primary species captured from the horse as well as in the traps. An. crucians, another species known to have a broad range of hosts, was found in varying percentages in all traps. Cx. erraticus, an ornithophilic species [19], was found in higher percentages in the traps than on the horse. Thus, the data acquired during the spring would point more towards mechanical traps catching primarily species of mosquitoes that have a broad pattern of both avian and mammalian hosts.

In contrast, the horse attracted a greater variety and higher abundance of species, most known to feed on mammalian hosts, than did the mechanical traps. While $C x$. salinarius was the most abundant species $(40.14 \%)$ found on the horse, $C x$. salinarius was found in a greater abundance in the mechanical traps (49.24-80.13\%). Ma. titillans represented $29.58 \%$ of the total catch from the horse, while the CDC-1012 trap captured $19.7 \%$ and the CFG traps captured between 4.13 and $9.17 \%$ during the 30-minute spring studies (Table 7). Ae. vexans, another species known to feed primarily on mammals $[18,20]$, was found in greater percentages on the horse $(7.04 \%)$ than in the traps $(0-2.4 \%)$.

During the spring, the relative abundance of species captured during the 30-minute study was found to be similar to the overnight trial with a few exceptions. The three main species captured by all traps and on the horse were $C x$. salinarius, $C x$. erraticus, and An. crucians. The primary species captured in both trials was $C x$. salinarius, and the difference in the proportion of $C x$. salinarius captured in the 30-minute study compared to the overnight study did not differ by more than $5 \%$ for any trap (Tables 7,8). The primary exception is in the percentage of $C x$. erraticus captured. Cx. erraticus populations are lower at dusk than during the remainder of the evening, as reflected by the 30-minute study at sunset and then the overnight study (Tables 7,8). This agrees with Snow [21] who recorded I activity throughout the night. The percent of Ma. titillans captured was also lower in the overnight collection when compared to the 30-minute period, especially with the CDC-1012 and the MMLiberty traps. The percentage of An. crucians captured in the overnight trials increased slightly from the 30-minute trials in all traps except the MM-X.

Differences in percentages of mosquito species captured during the summer and fall were even more dramatic than in the spring. Between May 17 and July 16, Cx. salinarius 
populations were still large enough to compete with $C x$. nigripalpus populations in percentages captured, at least in the MM-Pro and MM-X traps. The CDC-1012 captured a larger percentage of $C x$. salinarius and the MM-Liberty captured a higher percentage of $C x$. nigripalpus (Table 2). Between July 17 and September 30, between 85 and $91 \%$ of the total catch by all mechanical traps (Table 3 ) was $C x$. nigripalpus, a species known to shift host preference from birds to mammals [8]. Other species, some of which are mammalian feeders, captured during this experiment included Ma. titillans, $C x$. erraticus, and Ae. infirmatus, but none represented $>5 \%$ of the total catch of any trap in overnight trials. All mechanical traps showed their ability to attract and capture large numbers of $C x$. nigripalpus, considered to be an important WNV vector in north Florida, but they did not trap any other species in large numbers during this study.

The horse had a very different species composition than the traps during the summer and fall studies. Similar to the spring studies, mosquito species found on the horse were typically mammalian feeders or had an affinity for both avian and mammalian hosts [18]. Ma. titillans was the species found in the greatest abundance on the horse, representing $40 \%$ of the total catch. This contrasts dramatically with the mechcanical traps, none of which captured $M a$. titillans in percentages $>4.73$. (Table 3). Cx. nigripalpus represented only $27 \%$ of the species found on the horse, which contrasted with the higher percentages $(85.45-90.98 \%)$ captured by the mechanical traps during this same period. Other mammalian feeders found in higher abundance on the horse than in the traps included $\mathrm{Ae}$. infirmatus, and Psorophora spp. Ps. cyanescens, a species rarely found locally in mosquito traps, represented $6.65 \%$ of the mosquitoes vacuumed from the horse.

The Shannon-Weaver Diversity Indices indicate a relative degree of diversity for the mosquito species captured in traps or vacuumed from the horse (Table 5). Lower values indicate less diversity and more competition between the mosquito species for the resource being offered, i.e. the traps and the horse. Higher values indicate more diversity and less competition between the species [14]. Indices for the four traps during the May 17-July 16, 2003, study ranged from 0.83-0.94, indicating a relatively high and similar degree of diversity (Table 5). No trap captured $>31 \%$ of a single species and the other species captured constituted $<25 \%$ of the catch (Table 2 ). During the July 17 -Sept 30,2002 , study the horse had a relatively high degree of species diversity while the traps had a very low degree of species diversity (Table 5). For the horse, three mosquito species constituted between 15.63 and $39.76 \%$ of the catch. For the traps, $C x$. nigripalpus represented between 85.73 and $91.13 \%$ of the catch, with all other species representing $\leq$ $4.73 \%$ of the catch. During the 30-minute trapping study in April 2003, the diversity index of the horse was again greater than those of the traps for the same reason given above (Table 5). During the overnight study in April 2003, indices for the traps were lower than those in the May 17-July 16, 2002, study because of a higher percentage of captures of a single species Cx. salinarius.
All mechanical traps evaluated, except the HGM without $\mathrm{CO} 2$, can capture large percentages of suspected WNV vector species during the spring, summer, and early fall months. If mechanical traps are shown to be an effective means of preventing vector species from feeding on host animals, i.e., horses in this case, these would be useful tools for horse owners. The mechanical traps have the ability to attract Culex spp. in a given area and, on average, capture hundreds to thousands of these mosquitoes in a single night (Tables 1,8). However, the question remains as to whether these traps give a true reflection of an actual mosquito population. The species diversity of mosquitoes vacuumed from a primary host that differs from the species diversity of mosquitoes captured in mechanical traps in the same area indicates an attraction differential between the host and the traps. If traps were used for reduction of WNV vectors such as $C x$. nigripalpus on equine facilities, perhaps the virus could be somewhat controlled in a given area; however, the primary species feeding on the horses, such as Ma. titillans, would be reduced by a lesser extent.

\section{Trap catch}

In previous studies, CFG traps have been shown to have a higher mosquito yield than non-CFG traps $[22,23]$. However, our data indicate that the CDC-1012 trap performed as well or better than CFG traps in spring (Tables 6,8 ) and in summer and early fall (Table 1) under our study conditions of these studies. In all our studies, the primary mosquitoes captured by traps were Culex spp., $C x$. nigripalpus in particular. $C x$. nigripalpus is known to be attracted to light [24] and the light in the CDC1012 trap in our study may be why it performed as well as or better than the CFG traps.

This study shows that CDC-1012 and CFG traps have the ability to capture host-seeking mosquitoes despite the presence of large mammalian hosts in the immediate vicinity. Although the CDC-1012 trap did have a higher average rate of catch rate during the 2002 study than the other traps, the CFG traps were able to catch large numbers of mosquitoes each night as well.

Among the CFG traps, the MM-Liberty captured the fewest mosquitoes in the 2003 study. The MM-Pro and MM-X had similar mean catch rates throughout both studies, despite a different source of $\mathrm{CO} 2$ for each trap.

The mosquito attractant, 1-octen-3-ol, was not used in these studies because some WNV vectors, such as $C x$. nigripalpus, have a low affinity for this attractant [25-27]; however, $C x$. salinarius is the exception $[26,28]$. Data from the 2002 study (Tables 2,3) might suggest that a large mosquito population consisting primarily of $C x$. nigripalpus exists at the HTU. However, many species of Aedes, Anopheles, Coquillettidia, Mansonia, Psorophora, and Aedes are captured in larger numbers when $\mathrm{CO} 2$ is coupled with octenol $[25,26,28]$. The addition of 1-octen-3-ol may have changed the relative abundance of mosquito species captured in the mechanical traps by reducing the capture of some of the species originally targeted. This demonstrates some of the problems associated with capturing multiple species of targeted mosquitos with a single combination of traps and attractants.

Citation: Campbell CB, Kline DL, Hogsette JA, TenBroeck SH (2021) Species complex of mosquitos captured by mechanical traps and an equine host. Int J Vet Sci Res 7(2): 169-177. DOI: https://dx.doi.org/10.17352/ijvsr.000097 


\section{Trapping site differences}

The HTU is a large facility, and trap sites were located in unique areas. Some trap sites were located within a few feet of a water source, while other sites were located in open pasture. Relative abundance of individual species of mosquitoes trapped did not differ much by site in any study. During the 2002 study, Cx. nigripalpus was the primary mosquito trapped at every site, and all sites showed relatively similar results for every other species trapped (Table 4). Results were similar for the 2003 study, but $C x$. salinarius was the primary mosquito trapped at each site and all species were similarly abundant at all sites (Table 9). Based on trap catches, the mosquito population appeared to be generally uniform throughout the trapping area, and large numbers of Culex mosquitoes were highly attracted to all but the HGM traps at all trap sites.

\section{Summary}

The mechanical traps captured different species profiles than the horse and generally captured more total mosquitoes than the horse during the same trapping interval (Table 7). If the species profile of the mosquitoes recovered from the horse is the one the traps should also be attracting and capturing, improvement is needed to enable traps to do so at a rate equal to or better than that of the horse. The inability of traps to outcompete the host have been documented with other dipteran species [29]. It is interesting to note that mosquito species attracted by and those not attracted by 1-octen-3-ol were all vacuumed from the horse during the same trapping intervals. This reveals some of the prevalent limitations in current technology that prevent traps from competing more effectively with animal hosts.

\section{Acknowledgements}

We thank Michael Behrens for his assistance with the highresolution photos.

\section{References}

1. Burkett D, Lee WJ, Lee KW, Kim HC, Lee HI, et al. (2001) Light, carbon dioxide, and octenol-baited mosquito trap and host-seeking activity evaluations for mosquitoes in a malarious area of the Republic of Korea. J Am Mosq Control Assoc 17: 196-205. Link: https://bit.ly/30jKfgv

2. Burkett DA, Lee WJ, Lee KW, Kim HC, Lee HI, et al. (2002) Late season commercial mosquito trap and host seeking activity evaluation against mosquitoes in a malarious area of the Republic of Korea. Korean J Parasito 40: 45-54. Link: https://bit.ly/3IFHM1v

3. Centers for Disease Control and Prevention (1999) Update: West Nile-like vira encephalitis - New York, 1999. Morbidity and Mortality Weekly Report 48: 890892. Link: https://bit.ly/31 KabCZ

4. Cupp E, Stokes GM (1973) Identification of bloodmeals from mosquitoes collected in light traps and dog-baited traps. Mosq News 33: 39-41. Link: https://bit.ly/3s1vSZY

5. Darsie RF, Ward RA (1981) Identification and geographical distribution of the mosquitoes of North America, north of Mexico. Salt Lake City: University of Utah Printing Services. Link: https://bit.ly/3yoQHzE

6. Edman JD (1971) Host-feeding patterns of Florida mosquitoes. I. Aedes, Anopheles, Coquillettidia, Mansonia, and Psorophora. J Med Entomol 8: 687695. Link: https://bit.ly/3pRNzlz
7. Edman JD (1974) Host-feeding patterns of Florida mosquitoes. III. Culex (Culex) and Culex (Neoculex). J Am Mosq Control Assoc 11: 95-104. Link: https://bit.ly/3ymrtSn

8. Edman JD (1979) Host-feeding patterns of Florida mosquitoes (Diptera: Culicidae). VI. Culex (Melanoconion). J Med Entomol 15: 521-525. Link: https://bit.ly/3s8wtsu

9. Gentry $A B$ (2002) Evaluation of protection systems and determination of seasonality for mosquito and biting flies at the University of Florida Horse Teaching Unit [Master's thesis]. University of Florida, Gainesville 142. Link: https://bit.ly/3s2s1f0

10. Kemme JA, Van Essen PHA, Ritchie SA, Kay BH (1993) Response of mosquitoes to carbon dioxide and 1-octen-3-ol in southeast Queensland, Australia. J Am Mosq Control Assoc 9: 431-435. Link: https://bit.ly/3IGkhFo

11. Kline DL (1994) Olfactory attractants for mosquito surveillance and control: 1-octen-3-ol. J Am Mosq Control Assoc 10: 280-287. Link: https://bit.ly/33d2u8r

12. Kline DL (1999) Comparison of two American Biophysics mosquito traps: The professional and a new counterflow geometry trap. J Am Mosq Control Assoc 15: 276-282. Link: https://bit.ly/33jeGod

13. Kline DL, Mann MO (1998) Evaluation of butanone, carbon dioxide, and 1-octen-3-ol as attractants for mosquitoes associated with north central Florida bay and cypress swamps. J Am Mosq Control Assoc 14: 289-297. Link: https://bit.ly/3EPUOqT

14. Lewis LA, Teller LW (1967) The use of fluorescent tubes in a modified New Jersey light trap. Proc New Jersey Mosq Extermination Assoc 54: 163-170.

15. Loftin KM, Byford RL, Loftin MJ, Craig ME, Steiner RL (1997) Host preference of mosquitoes in Bernalillo County, New Mexico. J Am Mosq Control Assoc 13: 71-75. Link: https://bit.ly/3IKkp6F

16. Nasci RS (1984) Variations in the blood-feeding patterns of Aedes vexans and Aedes trivittatus (Diptera: Culicidae). J Med Entomol 21: 95-99. Link: https://bit.ly/3dMDo2o

17. O'Meara GF, Evans F (1983) Seasonal patterns of abundance among three species of Culex mosquitoes in a south Florida wastewater lagoon. Ann Entomol Soc Am 76: 130-133. Link: https://bit.ly/3DNkG5d

18. Rios LMV (2008) Identification of potential mosquito vectors of West Nile virus to horses in North Central Florida [Ph.D. dissertation]. University of Florida, Gainesville 136. Link: https://bit.ly/3GCkvvf

19. Rueda LM, Harrison BA, Brown JS, Whitt PB, Harrison RL, et al. (2001) Evaluation of 1-octen-3-ol, carbon dioxide, and light as attractants fo mosquitoes associated with two distinct habitats in North Carolina. J Am Mosq Control Assoc 17: 61-66. Link: https://bit.ly/3ylvOVJ

20. Samui KL, Gleiser RM, Hugh-Jones ME, Palmisano CT (2003) Mosquitoes captured in a horse-baited stable trap in southeast Louisiana. J Am Mosq Control Assoc 19: 139-147. Link: https://bit.ly/3dKHdVF

21. Sardelis MR, Turell MJ, Dohm DJ, O'Guinn ML (2001) Vector competence of selected North American Culex and Coquillettidia mosquitoes for West Nile virus. Emerg Infect Dis 7: 1018-1022. Link: https://bit.ly/31SWMsb

22. SAS Institute (2003) SAS version 9.1 for Windows. SAS Institute, Inc. Cary, NC Link: https://bit.ly/3yoKRxZ

23. Service M (1993) Mosquito Ecology Field Sampling Methods. London: Chapman and Hall. Link: https://bit.ly/3DNcr99

24. Shannon CE, Weaver W (1963) The mathematical theory of communication Urbana, IL: University of Illinois Press. Link: https://bit.ly/3IKzF3x

25. Snow WE (1955) Feeding activities of some blood-sucking Diptera with reference to vertical distribution in bottomland forest. Annu Entomol Soc Am 48: 512-521. Link: https://bit.ly/33iO5r

Citation: Campbell CB, Kline DL, Hogsette JA, TenBroeck SH (2021) Species complex of mosquitos captured by mechanical traps and an equine host. Int J Vet Sci Res 7(2): 169-177. DOI: https://dx.doi.org/10.17352/ijvsr.000097 
26. Stark LM, Kazanis D (Florida Department of Health, Bureau of Laboratories) (2001) Arbovirus Surveillance: Annual Summary Report 2001. Tampa, FL: FDH. Available from Florida Department of Health, Bureau of Laboratories, Tampa, FL 19.

27. Stark LM, Kazanis D (Florida Department of Health, Bureau of Laboratories) (2002) Arbovirus Surveillance: Annual Summary Report 2002. Tampa, FL: FDH. Available from Florida Department of Health, Bureau of Laboratories, Tampa, FL 20.
28. Tam TL, Hogsette J, TenBroeck S (2019) Can Attractive Sticky Traps Be Used to Protect Horses from the Bites of Stomoxys calcitrans (L.). J Econ Entomol 112: 2469-2473. Link: https://bit.ly/3oMV4B5

29. Zyzak M, Loyless T, Cope S, Wooster M, Day JF (2002) Seasonal abundance of Culex nigripalpus Theobald and Culex salinarius Coquillett in north Florida, USA. J Vector Ecol 27: 155-162. Link: https://bit.ly/3dJ76oL

\section{Discover a bigger Impact and Visibility of your article publication with}

\section{Peertechz Publications}

\section{Highlights}

* Signatory publisher of ORCID

* Signatory Publisher of DORA (San Francisco Declaration on Research Assessment)

* Articles archived in worlds' renowned service providers such as Portico, CNKI, AGRIS, TDNet, Base (Bielefeld University Library), CrossRef, Scilit, J-Gate etc.

* Journals indexed in ICMJE, SHERPA/ROMEO, Google Scholar etc.

* OAI-PMH (Open Archives Initiative Protocol for Metadata Harvesting)

* Dedicated Editorial Board for every journa

* Accurate and rapid peer-review process

* Increased citations of published articles through promotions

* Reduced timeline for article publication

Submit your articles and experience a new surge in publication services (https://www.peertechz.com/submission).

Peertechz journals wishes everlasting success in your every endeavours. 